\title{
CHINESE PRODUCT-SERVICE SYSTEM INNOVATIONS ENABLED VIA GOVERNMENTAL POLICIES: THE E- SCOOTER CASE
}

\author{
Yan, Zhang (1,2); \\ Larsson, Tobias (1); \\ Larsson, Andreas (1) \\ 1: Blekinge Institute of Technology; \\ 2: BIGmind Innovation
}

\begin{abstract}
Together with increasingly saturated and commoditized global markets companies are driven to shift their business focus, adopting a strategy where customer perceived value is in the spotlight, and where products are bundled with services to offer Product-Service Systems (PSS).

In this research we study the emergence of PSS solutions in the Chinese market via a selected case study on e-scooters, based on the governmental decision to ban fossil-fuel scooters in the late 90s and how this has spurred both a fossil-to-electric transformation and a product-to-function transformation. As seen in this research PSS is also an approach that is working well in the Eastern society and especially in China, based on governmental policies. It is gradually being adopted and applied in local industries significantly by China's leading internet companies (Didi, Alibaba etc). The PSS concept represented by e-bike cases in China has gradually penetrated into different industries. With governmental decisions as the key turn-point, it can be seen in practice and development that China's related service industry is using e-bike PSS to carry out the new business model from selling e-bikes to providing service-oriented solutions.
\end{abstract}

Keywords: Product-Service Systems (PSS), Case study, Circular economy

\section{Contact:}

Larsson, Tobias

Blekinge Institute of Technology

Mechanical Engineering

Sweden

tobias.larsson@bth.se 


\section{INTRODUCTION}

The idea of a manufactured goods as the main, sometimes the only, value carrier for customers is predominant in product design and development literature for engineers, e.g., (Ulrich and Eppinger, 2012). However, today's advances in digitalization confronts this type of product development tradition. Digitalization transforms our society, and brings consequences, not only for how products are produced and consumed, but also for how development work is organized. Shifts in industry - from the early industrialization with steam power and mechanization, to electrical energy and mass production, further to automation and electronics, and now the turn into Industry 4.0 with for example Internet of Things and networks - have never had such an impact on society and human life as they have today. This is due to the fact that e.g., locations of factories become less important, since digitalisation enables disconnection between physical locations. However, global supply chains become increasingly crucial (i.e., the pandemic showed us that) (Strange \& Zuchella, 2017) as Industry 4.0 goes beyond in-house automation, to bring about societal interconnectedness, where customers, e.g., share their user data with companies, and companies create businesses from that data. Together with increasingly saturated and commoditized global markets, companies are driven to shift their business focus towards a strategy where customer-perceived value is in the spotlight, and where products are bundled with services to offer Product-Service Systems (PSS) (Baines et al., 2007). Product-service systems (PSS) emerged as a response to make both production and consumption sustainable, for example by reducing waste by reuse, remanufacturing and repair, which is similar to the contemporary recommendation of a circular economy to guide sustainable development. The emergence of this 'servitization' (Vandermerwe, 1988) trend challenges traditional product-based business models, stressing the dematerialization of the physical artefacts (Bey and McAloone, 2015) and the creation of restorative and regenerative systems that decouple economic growth from environmental impact, and that generate new revenue streams out of extending the residual value of products. Despite the promises of PSS, manufacturers continue to struggle for the optimised financial performance by integrating products and services. For example, they are encountering the so-called 'service paradox', where substantial investment in services does not bring about the expected financial returns. Scholars argue that this is, to a large degree, due to the insufficient theoretical explanation (Posselt \& Roth, 2017) and the lack of a systems approach in PSS (Rondini et al., 2017). In a PSS context, a systems approach means the focus of interrelatedness between products and services, between product and service organisations, and between actors in a PSS network.

Since PSS can be seen as many different combinations of products (tangibles) and services (intangibles) it is not possible to visually identify whether a solution is a PSS or not, even when the PSS is right in front of you. Its value purpose may be any of the 8 PSS categories in Figure 1, below, ranging from pure product-based to pure service-based value contribution. This makes it difficult to discuss successful PSS designs, as it is hard to know the "design intent" of the solutions. Was it merely a hardware-centric product design where a service perspective was added as an aftermarket consideration or was it a PSS design from the ground up? 


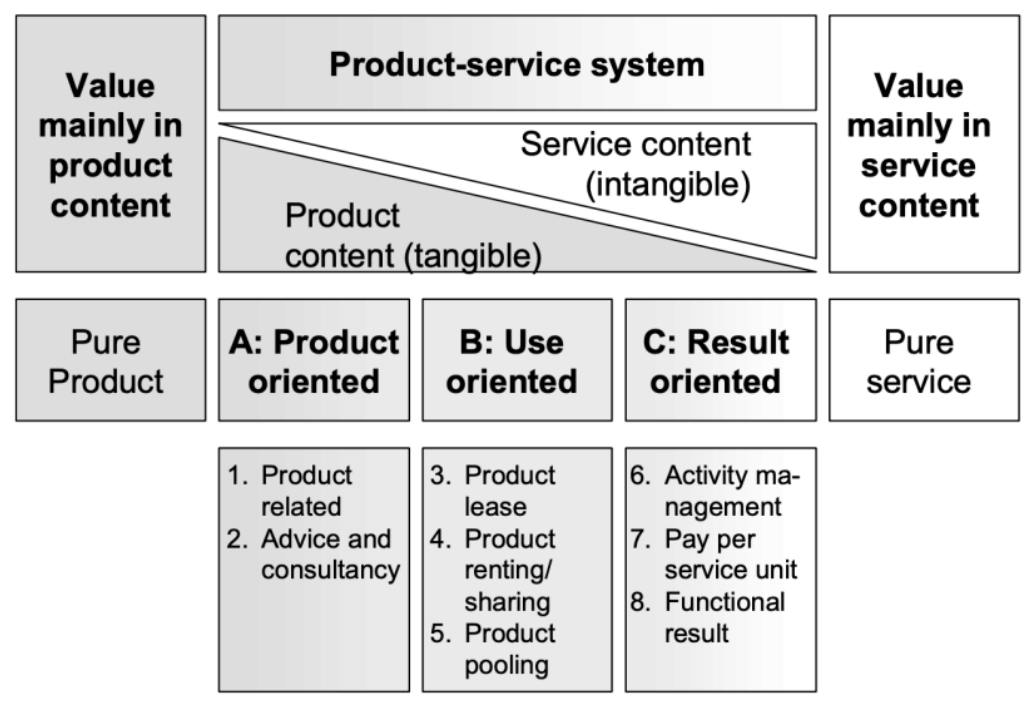

Figure 1. Main and subcategories of product-services (Tukker and Tischner, 2006)

There are some industry case study papers on PSS cases (Kim, 2017), but it is difficult to infer the design intent and the main drivers behind the solutions. Despite the wide range of benefits these models could provide, 'the adoption of such business strategies is still very limited because it often involves significant corporate, cultural and regulatory barriers' (Ceschin, 2013 p.74). Consequently, research has explored the barriers responsible for constraining the application of PSS models and the types of government policy interventions that could help to promote PSS activity (Mont and Lindhqvist, 2003; Ceschin and Vezzoli, 2010; Tukker et al., 2008). This paper examines how 'demand pull' government policies might cultivate a greater demand for PSS activity and solutions.

\section{RESEARCH METHODOLOGY}

The presented study is industry field research including literature review, field observation and user interviews. The Design Research Methodology (DRM) (Blessing and Chakrabarti, 2009) was used as a guiding framework throughout the research. After conducting the initial Research Clarification (RC) stage, the authors undertook a comprehensive Descriptive Study I (DS-I) to obtain a sufficient understanding of the situation at hand. Relevant contributions were collected through a systematic search in the Scopus and Google Scholar databases and further complemented through snowballing (Wohlin, 2014) to find additional literature. Material was also collected in local context, with photos to quickly record the PSS transformation. The empirical data gathering activities in DS-I are based on a multiple case study approach (Yin, 2013).

\section{DEMAND PULL VIA GOVERNMENTAL DECISIONS}

Innovation systems theory has been widely used in finding how government policy could make positive improvements to the innovation process of development and deployment. At the same time, technology innovation has always been the core of the past (Hekkert et al., 2007), often with a strong sustainable development focus (Krozer and Nentjes, 2008). Here, innovation is defined as a non-linear and evolutionary process (Grubler et al., 2012; Truffer et al., 2012). According to the form of government policy, many of the innovation activities can be supported through either a 'supply push' or a 'demand pull' policy. The generation of new knowledge is affected by a government-funded 'supply push' policy, including company tax deductions for R\&D investment, the government helping companies to promote and share knowledge in the industry, and funding demonstration projects (Nemet, 2009). On the other hand, 'demand pull' policies can make fast and major impact on the demand for innovations and development (Grubler et al., 2012).

\subsection{Demand pull to support PSS}

By applying this framework to the types of PSS 'demand pull' policies that have been identified in literature we found that companies should be encouraged to invest more in resource utilization, efficient operation and service-based solutions. It is also necessary to use regulations based on environmental costs incurred in production and consumption to regulate activities of company. (Mont and Lindhqvist, 
2003; Ceschin and Vezzoli, 2010). About informative policies, the establishment of a learning plan allows suppliers and consumers to deepen their understanding of the PSS model, and encourages the engagement of public sector and companies to participate in this learning plan. (Tukker et al., 2008; Ceschin and Vezzoli, 2010). To stimulate public sector PSS engagement, some authors (Larsen and Svane, 2005; Tukker et al., 2008; Ceschin and Vezzoli, 2010) recommend that the PSS solution for environmental protection and eco-efficiency improvement should be included in the government procurement procedures, prior to product sales.

\subsection{Chinese electric bike classification}

Electric bicycles have the characteristics of easy riding, faster speed than ordinary bicycles, essentially both time-saving and labor-saving with an overall added convenience factor. Since the first electric bicycle appeared in China in the 1990s, it has been widely promoted and applied, with the number of electric bicycles growing from 290,000 in 2000 to 36 million in 2019. (Chinamotor, 2020).

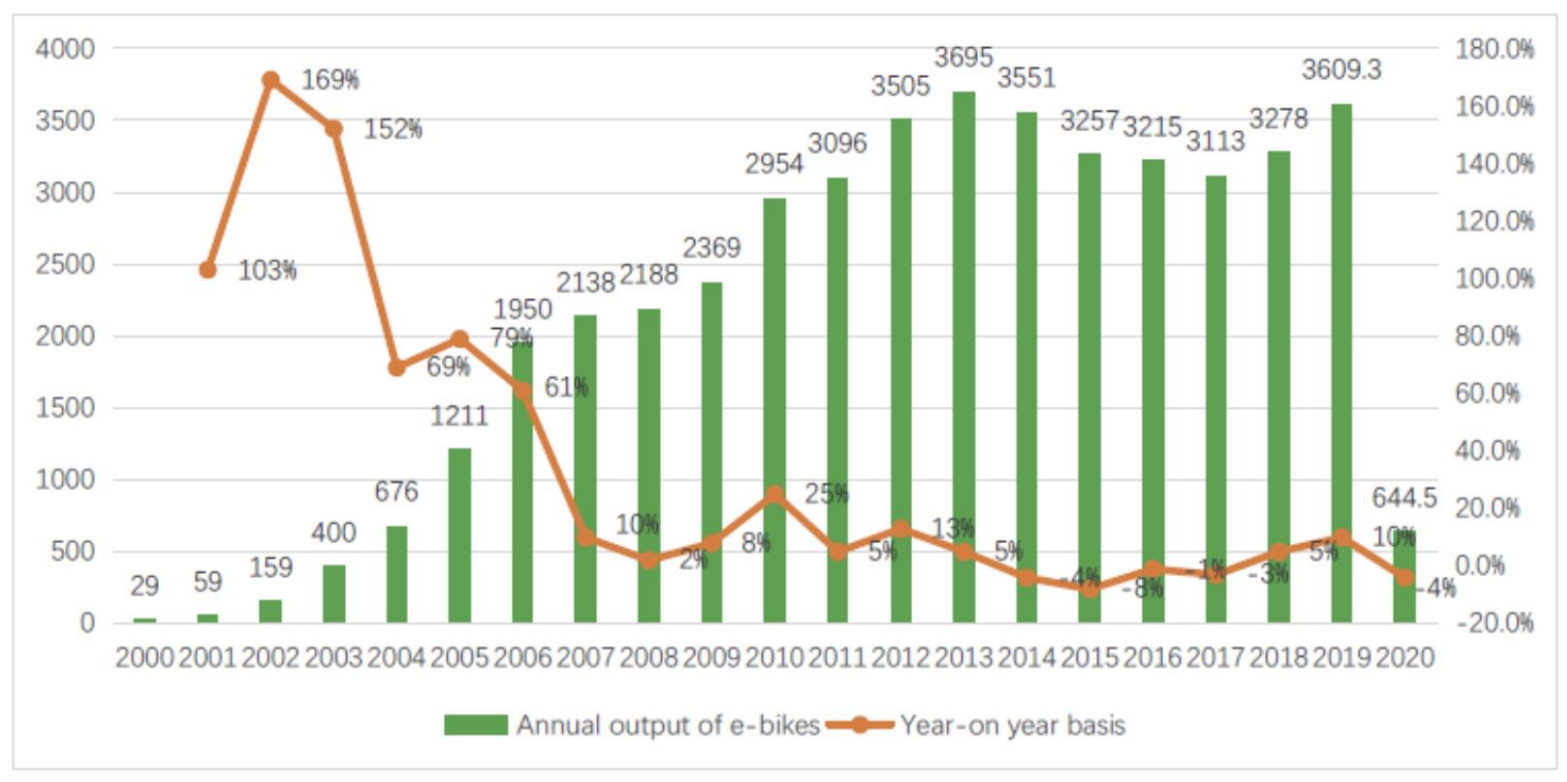

Figure 2. Annual output of electric bikes in 2000-2020 (10.000 units) (Chinamotor, 2020).

Two-wheeled vehicles (2WVs), e.g. bicycles, electric bikes (e-bike), electric scooters (e-scooters), motor scooters, motorcycles, have historically been an important component of traffic throughout China and many other developing countries. Gasoline-powered motor scooters (GMSs) used to make up a larger percentage of the overall $2 \mathrm{WV}$ population; however, beginning in the late 1990s, many large cities (population $>1$ million) and most capital cities have stopped licensing these vehicles. Chinese consumers are shifting from bikes (or public transit) to e-scooters as they demand more flexible, convenient, and comfortable (at low cost) mobility. In sales of two-wheelers, electricpowered vehicles have gained over the past decade. E-scooters were originally invented to make cycling easier for the elderly (Parker, 2014). Now e-scooters are increasingly replacing not only human-powered bicycles, but also gasoline-powered two-wheelers. It is striking that in China the electric two-wheeler market has grown very strongly from almost nothing to being a substantial activity in a little over ten years (Weinert, 2007). There is another important factor that has to be taken into account to explain the ongoing transition to e-scooters. For decades, high emissions from gasoline-powered two wheelers and air pollution have been a thorn in the side of transport planners and policy makers. Their concerns translated into a variety of policies throughout Asian countries that aim at restricting the use of these vehicles. These policies also partially explain the rapid transition to e-scooters on Chinese roads, where gasoline-powered two-wheelers have faced government bans. E-scooters, even scooter-style electric bikes (SSEBs), have been treated as nonmotorized modes and granted access to bike lanes (Weinert, 2007). Hence, e-scooters have become a very cost-efficient alternative for low- and middle-income households, while retaining the general advantages of two-wheelers (Rose, 2012). Since 1997, many Chinese cities have started to partially 
or completely ban motorcycles and scooters. As of 2009, motorcycles and scooters were banned or restricted in over 170 cities (Cao and Fan, 2009). While the bans did not challenge the reliance on the private car, they did create an opportunity for spontaneous emergence of two-wheel battery electric vehicles.

\subsection{Challenges of the E-bikes green environment}

The implementation of energy-saving certification standards for e-bikes needs to be strengthened. There are currently energy-saving standards for electric motorcycles and e-bikes, but they are not enforced. There is a relative lack of energy-saving core technologies, and the technology to improve the energy-saving of electric vehicles lacks independent research and development capabilities in key core components and system software for batteries, motor drive and control, and energy management. At the same time there is insufficient motivation for energy-saving technological innovation in the Chinese e-bikes companies. China's e-bike companies have relatively low technical access requirements, mature business models and strong reproducibility. However, e-bike companies lack energy conservation awareness, fail to highlight green development and establish long-term mechanisms, resulting in low investment in energy-saving technology research and development. At the consumer level, consumers are relatively more concerned about product prices, resulting in the low-end development trend of the industry and affecting the R\&D vitality of enterprises (Rose, 2012).

\subsection{PSS industry segmentation}

The main purpose of the e-scooter PSS segmentation (see Figure 3, below) is to first identify the types of domestic industries that could benefit from e-scooter growth, and subsequently identify the main types of use cases according to the respective industry segments. Despite the rapid penetration and widespread use of e-scooters in various industries in China, there have been no previous research efforts to subdivide the e-scooter industry applications from the perspective of PSS and summarize the PSS model. Through the understanding of the industry in China, the service mode of e-scooters for the industry was analyzed, and the corresponding PSS type was found among the 8 PSS types in Figure 1 (Tukker, 2006). The authors of the paper chose four PSS models related to China (1. Product related, 2. Product renting, 3. Pay per service unit, 4. Functional result) into each segmentation. Case study research and field research was performed to identify China's e-scooter applications together with leading local companies in a wide range of industries. According to this research, e-scooters are currently applied in 12 industries in China, covering a total of 29 industry segments. This paper focuses on three representative local industries with a relatively strong e-scooter PSS development: Catering, Logistics and Retail. 


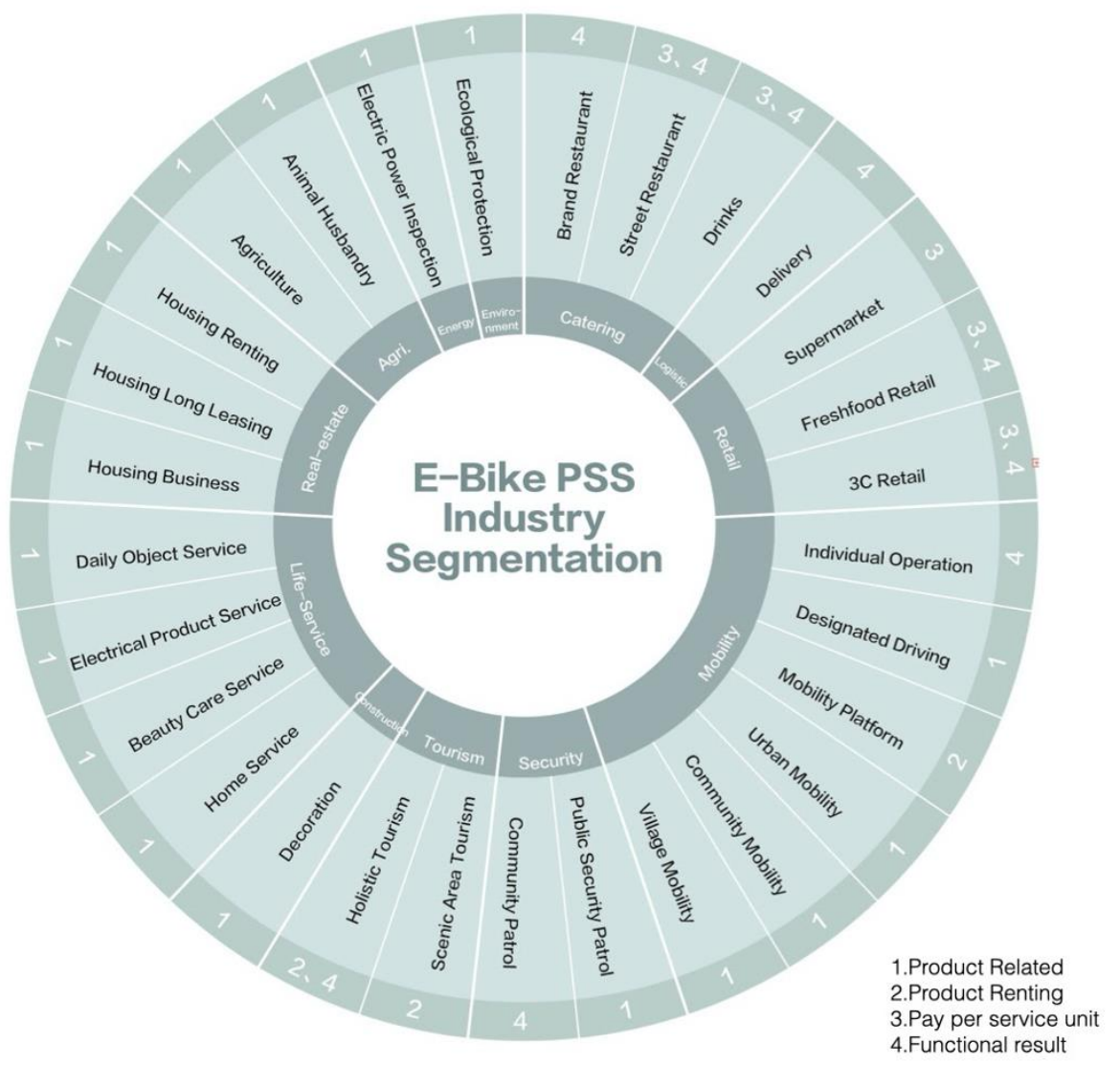

Figure 3. E-bike PSS industry segmentation into classes.

1. Catering Industry: This industry contains two primary use cases related to e-scooters. The first case is the delivery service, where the two-wheel e-scooters help the delivery rider to deliver the meal from the store to the customer. The second case is food vendors, who use e-scooters as a mobile store to help vendors run their businesses.

PSS model: Pay per service unit (PSS type 7, result oriented)

The company provides services instead of selling products, but providing a complete customer journey and standard service processes. In this process, the pure service received by the consumer.

Local Case: Meituan Group owns China's largest e-scooter delivery system, and its takeaway branch is China's leading online ordering platform. Meituan has 250 million takeaway users, more than 2 million cooperative merchants, more than 500,000 active delivery riders, covering more than 1,300 cities, and fulfilling 21 million orders per day. (Cen Song et al., 2020). The core of Meituan's service is speed (delivery within 30 minutes), and the platform uses its unique algorithm optimization to deliver takeaway orders, allowing riders to deliver in the optimal order. Riders use Meituan's mobile phone app for navigation and delivery management, and try to meet the needs of more merchants and customers every time they go out to maximize efficiency. Meituan's e-scooters have their own energy replacement system, which enables uninterrupted riding of the vehicles during the delivery process and guarantees energy. 


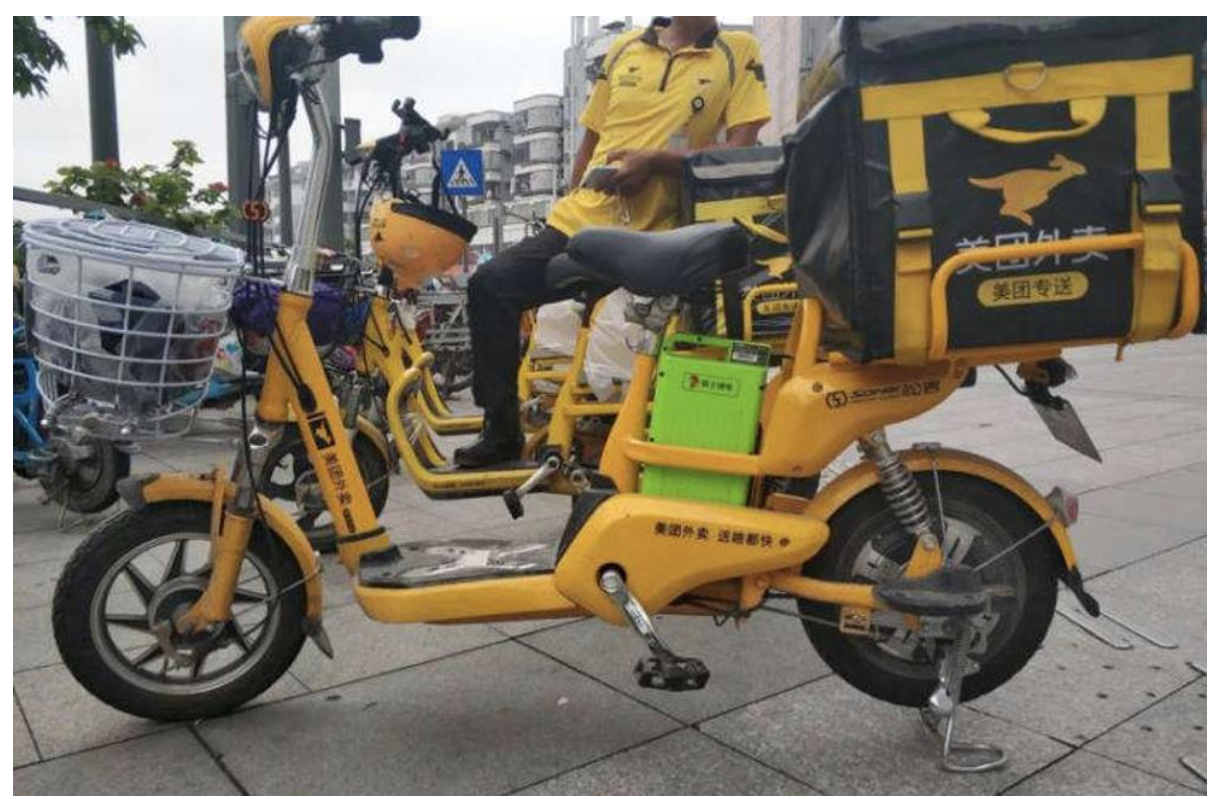

Figure 4. Meituan e-scooters delivery service (photo from www.baidu.com) (Meituan, 2020).

2. Retail Industry: This industry includes all distribution services in the retail industry. Since different retail categories have different requirements for delivery services, the delivery rider riding the e-bikes must also meet the requirements of other additional conditions while delivering the items from the market to the customer.

PSS model: Functional Result (PSS type 8, result oriented)

Here, the customer and provider in principle agree on a result, and there is no predetermined product involved.

Fresh Food Retail: In the fresh food retail industry, the requirements for distribution services are more time-sensitive, and the temperature of the distribution process needs to be strictly controlled. Users can order through the take-away platform and receive fresh products within a limited time and ensure freshness.

Local Case: Hema is a new retail format that Alibaba has completely restructured from offline supermarkets. It is a new retail platform driven by data and technology. Hema hopes to create a community-based one-stop new retail experience center for consumers (Birthwhistle, 2018). The core of Hema's service is keeping food fresh. Consumers can place an order on the Hema App. One of the biggest features of Hema is its unique route calculation for supporting e-scooter's fast and fresh delivery. All deliveries within 3 kilometers of the store will be delivered within 30 minutes. Hema has its own well trained delivery team, and Hema uses a self-developed refrigerator box to install on the escooters to ensure the result of the fresh food delivery to the customer, and the customer pays the bill to Hema. The e-scooter system let Hema go beyond merely fast delivery and always maintain the freshness and quality of food. 


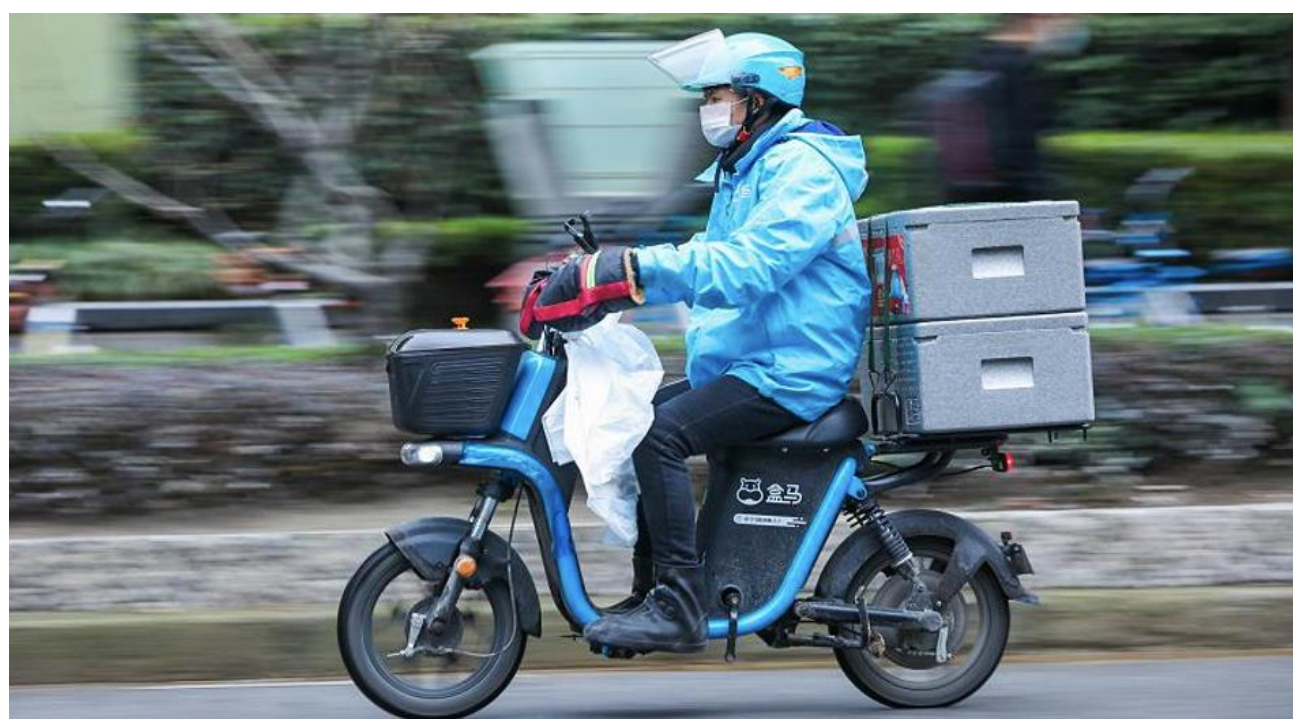

Figure 5. Hema e-scooter delivery service (photo from www.baidu.com).

3. Logistics Industry: Logistics is the process of the physical flow of goods from the supply place to the receiving place. According to actual needs, the functions of transportation are organically combined to achieve user requirements.

PSS model: Pay per service unit (PSS type 7, result oriented)

The PSS still has a fairly common product as a basis. Yet the user no longer buys the product, but pays for the output of the product according to the use level.

Local Case: SF Express is a leading express logistics integrated service provider. It has initially established the ability to provide customers with integrated logistics solutions. It not only provides logistics services at the distribution end, but also extends to the production, supply, sales, and distribution at the front end of the value chain. The core of SF's PSS is safety. SF Express has a selfdeveloped smart information network and three-wheeled e-scooter system, which can provide a variety of delivery solutions when customers have express delivery needs. Transportation safety is the core, including vehicle protection of goods during transportation, vehicle transportation safety and personal privacy safety. (Rongwei Gu et al., 2019).

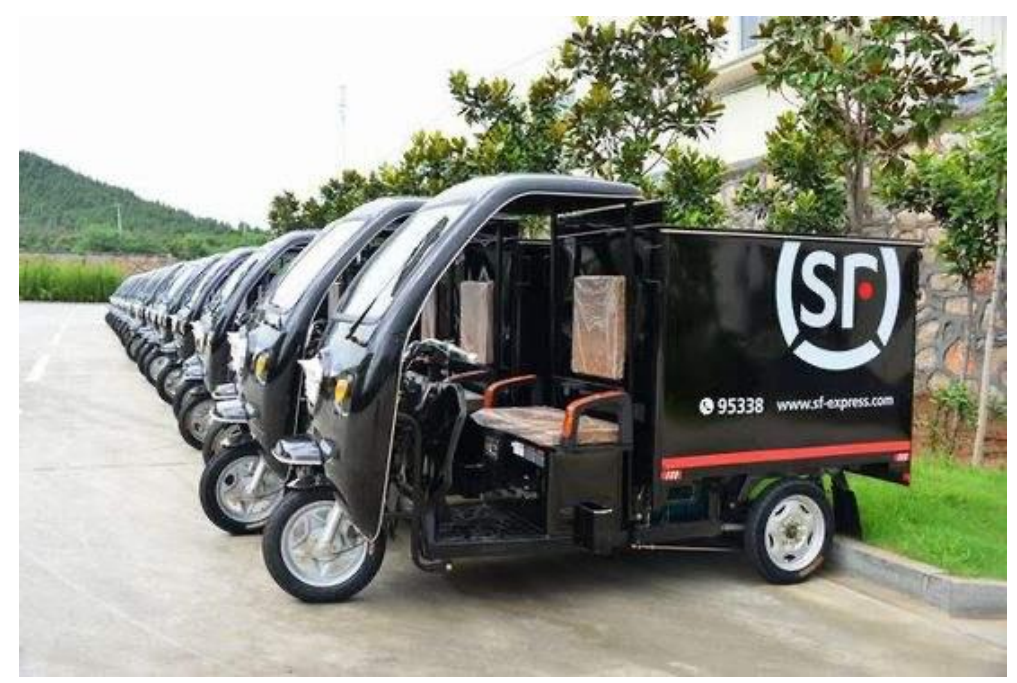

Figure 6. SF express e-bikes delivery service 


\section{RESULTS AND DISCUSSION}

Product-service systems (PSS) emerged as a response to make both production and consumption sustainable of the industry in global countries, with its origins from western industrial society and its manufacturing enterprises for innovation and development. As seen in this research it is also an approach that is working well in the Eastern society and especially in China, based on governmental policies. It is gradually being adopted and applied in local industries significantly by China's leading technology companies (Didi, Alibaba etc). At the same time, the large-scale usage of e-bikes on the market has also brought negative impacts on environmental sustainability. There is a lack of waste battery recycling and treatment facilities specifically provided for e-bike riders. The large-scale manufacturing of bike frames and batteries has caused environmental problems during the manufacturing phase. The environmental impact of the e-bike system during the use phase is also required to be calculated and evaluated.

The PSS concept represented by e-scooter cases in China has gradually penetrated into different industries. With governmental decisions as the key turn-point, it can be seen in practice and development that China's related service industry is using e-scooter PSS to carry out the new business model from selling e-scooters to providing service-oriented solutions. In the process of sustainable energy saving and emission reduction from traditional fuel to new green energy, the government has adopted active policies to promote the industry from manufacturing and selling e-scooters to operating e-scooter PSS for China's leading companies, industries and cities.

\section{ACKNOWLEDGMENTS}

The financial support from the Knowledge Foundation via the Model Driven Development and Decision Support research profile is highly appreciated.

\section{REFERENCES}

Baines, T.S.; Lightfoot, H.W.; Evans, S.; Neely, A.; Greenough, R.; Peppard, J.; Roy, R.; Shehab, E.; Braganza, A.; Tiwari, A.; Alcock, J.R.; Angus, J.P.; Bastl, M.; Cousens, A.; Irving, P.; Johnson, M.; Kingston, J.; Lockett, H.; Martinez, V.; Michele, P.; Tranfield, D.; Walton, I.M.; Wilson, H. State-of-the-art in productservice systems. J. Eng. Manuf 2007, 221(10), pp. 1543-1552. https://dx.doi.org/10.1243/09544054JEM858

Bey, N., \& McAloone, T. C. (2006). From LCA to PSS - Making leaps towards sustainability by applying product/service-system thinking in product development. In Proceedings of LCE 2006: 13th CIRP International Conference on Life Cycle Engineering (pp. 571-576). Leuven, Belgium: Katholieke Universiteit Leuven. (CIRP Life Cycle Engineering conference series; No. 13).

Birtwhistle, T. (2018), “China's next retail disruption: End-to-end value chain digitisation”, PWCC Global Consumer Insights Survey Report, Vol. 38, pp.22.https://www.pwccn.com/en/retail-andconsumer/publications/global-consumer-insights-survey-2018-china-report.pdf

Blessing, L. T., \& Chakrabarti, A. (2009). DRM: A Design Research Methodology. London: Springer.

Cao, B.Z., Fan, J.F., 2009. ('The analysis of the impact of 'motorcycle bans' policy on Jiangmen motorcycle industry'). Sci. Technol. Ind. 9 (1), 5-8.

Cen Song 1, Chunyu Guo 1, Kyle Hunt 2, Jun Zhuang 2. (2020), “An Analysis of Public Opinions Regarding Take-Away Food Safety”, Journal of Foods 2020, Foods 2020, 9, 511; https://dx.doi.org/10.3390/foods9040511

Ceschin, F., 2013. Critical factors for implementing and diffusing sustainable product-Service systems: Insights from innovation studies and companies' experiences. J. Clean. Prod. 45, 74-88.

Ceschin, F., Vezzoli, C., 2010. The role of public policy in stimulating radical environmental impact reduction in the automotive sector: the need to focus on product-service system innovation. Int. J. Automot. Technol. Manag. 10, 321-341.

China motor. (2020), "Development Status and Trends of China's E-bike Industry in 2020- A cluster, scale and technology-driven development direction". https://chinamotorworld.com/development-status-and-trends-ofchinas-e-bike-industry-in-2020/

Edler, J., 2013. Review of Policy Measures to Stimulate Private Demand for Innovation. Concepts and Effects. In: Nesta Working Paper Series. Manchester Institute of Innovation Research.

Ericson, A. A need-based approach to product development. PhD dissertation, Division of functional product development. Department of applied physics and mechanical engineering. Luleå university of technology, 2007.

Grubler, A., Aguayo, F., Gallagher, K., Hekkert, M., Jiang, K., Mytelka, L., Neij, L., Nemet, G., Wilson, C., 2012. Chapter 24-Policies for the Energy Technology Innovation System (ETIS). Global Energy 
Assessment - Toward a Sustainable Future. Cambridge University Press, Cambridge, UK and New York, NY, USA and the International Institute for Applied Systems Analysis, Laxenburg, Austria.

Hekkert, M.P., Suurs, R.A.A., Negro, S.O., Kuhlmann, S., Smits, R.E.H.M., 2007. Functions of innovation systems: a new approach for analysing technological change. Technol. Forecast. Soc. Change 74, 413-432.

Heiko, Gebauer., Elgar, Fleisch., Thomas Friedli.,2005. Overcoming the Service Paradox in Manufacturing Companies. European Management Journal. Vol.23, issue1, February 2005, (pp. 14-26).

iiMedia.(2020), iiMedia Life and Travel Industry Research Center, "2020 China Shared E-bikes Safety Management Special Research Report” pp. 72-75. https://www.iimedia.cn/c400/72366.html

Kim, Yong Se; Choe, Yunhwa: 15 industry cases of product-service systems for manufacturing companies and their comparison framework. In: Proceedings of the 21st International Conference on Engineering Design (ICED17), Vol. 3: Product, Services and Systems Design, Vancouver, Canada, 21.-25.08.2017.

Krozer, Y., Nentjes, A., 2008. Environmental policy and innovations. Bus. Strategy Environ. 17, $219-229$.

Larsen, K., Svane, O€., 2005. Routines and Communities of Practice in Public Environmental Procurement Processes. CESIS Electronic Working Paper Series

Meituan. (2020), "Meituan Takeaway Baidu Baike, platform development and operation data", https://baike.baidu.com/item/metuan/15824335?fr=aladdin

Mont, O.K., Lindhqvist, T., 2003. The role of public policy in advancement of product service systems. J. Clean. Prod. 11, 905-914.

Nemet, G.F., 2009. Demand-pull, technology-push, and government-led incentives for non-incremental technical change. Res. Policy 38, 700-709

Parker, A.A. Green Products to Help Move the World Beyond Oil: Power Assisted Bicycles. Proc., 37th Annual Conference of the Australian and New Zealand Solar Energy Society, Geelong, Victoria, Australia, 1999. http://solar.org.au/papers/99papers/PARKER.pdf. Accessed June 14, 2014.

Posselt, T., Roth, A., 2017. Microfoundations of organizational competence for servitization. J. Competences, Strategy, Manag. 9, 85-107.

Rongwei G., Yiqun L., Yuhang M. (2019), “The Choice of Non-Market Strategy for Private Express Enterprises in China", 2019 2nd International Workshop on Advances in Social Sciences, Francis Academic Press, UK. Vol. 20 No. 3, pp. 209-211.

Rondini, A., Tornese, F., Gnoni, M.G., Pezzotta, G., 2017. Hybrid simulation modelling as a supporting tool for sustainable product service systems : a critical analysis. Int. J. Prod. Res. 1-14.

Rose, G. E-Bikes and Urban Transportation: Emerging Issues and Un- resolved Questions. Transportation, Vol. 39, No. 1, 2012, pp. 81-96.

Strange, R.; Zucchella, A. Industry 4.0, global value chains and international business. MBR, 2017, 25, 174-184. https://doi.org/10.1108/MBR-05-2017-0028.

Truffer, B., Markard, J., Binz, C., Jacobsson, S., 2012. Energy Innovation Systems: Structure of an Emerging Scholarly Field and its Future Research Directions. Eawag/Circus, Dubendorf \& Chalmers University, Gothenburg, Switzerland/Sweden.

Tukker, A., Emmert, S., Charter, M., Vezzoli, C., Sto, E., Munch Andersen, M., Geerken, T., Tischner, U., Lahlou, S., 2008. Fostering change to sustainable consumption and production: an evidence based view. J. Clean. Prod. 16, 1218-1225.

Tukker, A., U. Tischner New business for old Europe. Product services, sustainability and competitiveness Greenleaf Publishers, Sheffield, UK (2006)

Vandermerwe, S.; Rada, J. (1988). Servitization of business: adding value by adding services. Eur Manag J 1988, 6(4), 314-324.

Wohlin, C., (2014). Guidelines for snowballing in systematic literature studies and a replication in software engineering, in Proc. of the 18th International Conference on Evaluation and Assessment in Software Engineering, London, England, pp. 1-10

Yin, R. K. (2013). Case study research: Design and methods. Sage publications.- 